\title{
Assessing the role of syringe dispensing machines and mobile van outlets in reaching hard-to-reach and high-risk groups of injecting drug users (IDUs): a review Md Mofizul Islam*1,3 and Katherine M Conigrave ${ }^{2,3}$
}

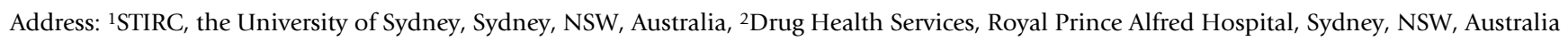
and ${ }^{3}$ Faculty of Medicine, the University of Sydney, Sydney, NSW, Australia

Email: Md Mofizul Islam* - mikhokan143@yahoo.com; Katherine M Conigrave - katec@med.usyd.edu.au

* Corresponding author

Published: 24 October 2007

Harm Reduction Journal 2007, 4:14 doi:10.1186/1477-75/7-4-14
Received: 5 March 2007

Accepted: 24 October 2007

This article is available from: http://www.harmreductionjournal.com/content/4/I/14

(c) 2007 Islam and Conigrave; licensee BioMed Central Ltd.

This is an Open Access article distributed under the terms of the Creative Commons Attribution License (http://creativecommons.org/licenses/by/2.0), which permits unrestricted use, distribution, and reproduction in any medium, provided the original work is properly cited.

\begin{abstract}
Reaching hard-to-reach and high-risk injecting drug users (IDUs) is one of the most important challenges for contemporary needle syringe programs (NSPs). The aim of this review is to examine, based upon the available international experience, the effectiveness of syringe vending machines and mobile van/bus based NSPs in making services more accessible to these hard-to-reach and highrisk groups of IDUs. A literature search revealed 40 papers/reports, of which 18 were on dispensing machines (including vending and exchange machines) and 22 on mobile vans. The findings demonstrate that syringe dispensing machines and mobile vans are promising modalities of NSPs, which can make services more accessible to the target group and in particular to the harder-toreach and higher-risk groups of IDUs. Their anonymous and confidential approaches make services attractive, accessible and acceptable to these groups. These two outlets were found to be complementary to each other and to other modes of NSPs. Services through dispensing machines and mobile vans in strategically important sites are crucial elements in continuing efforts in reducing the spread of HIV and other blood borne viruses among IDUs.
\end{abstract}

\section{Introduction}

HIV transmission associated with sharing of contaminated injecting equipment is now a global problem, with more than 110 countries having reported HIV transmission in this context [1]. World Health Organisation (WHO) estimates approximately $10 \%$ of all new HIV infections globally can be attributed to the sharing of contaminated injecting equipment [2]. In many parts of the world injecting drug users (IDUs) comprise a far higher proportion of new HIV infections, for example $72 \%$ of new HIV infections in Ukraine [3]. An injecting drug user infected with HIV can cause a cascade of new infections in other individuals, not only through sharing of contami- nated injecting equipment but also through sexual and perinatal transmission. Hepatitis $C$ and $B$, two other blood-borne viruses, are far more easily transmitted by blood-blood contact than HIV $[4,5]$ and carry the risk of cirrhosis.

Having experienced the limited outcomes of efforts to significantly eliminate supply and demand for illicit drugs by law enforcement, and in the face of rising prevalence of HIV and other blood-borne viruses, there has been a growing urgency to implement more effective prevention responses to prevent transmission of blood-borne viruses among IDUs. Therefore, authorities have adopted a more 
realistic approach to drug policy, termed as 'Harm Reduction' or 'Harm minimisation' in which reduction of adverse consequences of drug use is valued as high priority at least as important as reducing demand and supply. The Needle Syringe Program (NSP) or Needle Exchange Program (NEP) is a fundamental component of harm reduction that supports access to sterile injecting equipment for IDUs and discourages sharing of used injecting equipment. Preventive measures through NSP will remain the most effective tool available to reduce the spread of HIV among and from IDUs until an effective and widely deployed vaccine is available.

NSP disease prevention efforts are dependent in part on their ability to attract and maintain contact with IDUs so that injecting equipment, and also education and referrals can be provided. However, IDUs often avoid service providers until a crisis emerges, because they perceive interactions in service settings can be embarrassing, degrading, unhelpful and can be offered at locations and times incompatible with their lives [6]. To overcome these difficulties, a variety of measures have been developed to improve access to and utilization of sterile injecting equipment, and to increase choice for users. These include several methods for distribution, sale or exchange of injecting equipment such as conventional NSPs (housed in a fixed location where IDUs are attended by health staff), pharmacy-based distribution or exchange, dispensing machines (that either sell injecting equipment, provide it for free or in exchange for used equipment) and outreach programmes - often using a mobile van or bus and sometimes through home-visits. In addition, health education and safer injecting advice has been provided. Services through dispensing machines and mobile vans have been reported to be responsive to a wider range of IDUs and most importantly to hidden and harder-toreach IDUs in the community, who for several reasons do not or cannot attend conventional NSPs $[7,8]$. The aim of this review is to examine the available evidence for the effectiveness of syringe dispensing machines and mobile van or bus based NSPs in making services accessible to hard-to-reach and high-risk groups of IDUs.

\section{Methods}

Journal publications, conference presentations and proceedings, evaluation reports, and other relevant organizational reports relating to supply of sterile injecting equipment through dispensing machines and/or mobile vans were identified by a comprehensive search of electronic databases such as Medline, Medscape, Current Contents, HealthSTAR, CAB Abstracts, Aidsline, Sociological Abstracts and CINAHL. In addition, experts involved with development and evaluation of current programs or policy were contacted for official reports, policy documents or unpublished materials. In total, 40 papers/ reports were found that primarily focused on dispensing machines and/or mobile vans, of which 18 focused on dispensing machines and 22 on mobile vans.

\section{Results \\ Introduction of dispensing machines and mobile vans to NSP}

Syringe dispensing machines were first introduced in Copenhagen, Denmark in June 1987 [9] then a few months later in Larvik, Norway. Subsequently they were introduced in several European countries including Switzerland, Germany, France, Italy, the Netherlands, Austria, and also in Australia and New Zealand. These are automatic commercial dispensing machines that exchange new for used syringes, or provide sterile equipment for a coin or free-of-cost. These machines are also known as 'syringe exchange machines', 'syringe vending machines', 'syringe automat' or 'FITPACK ${ }^{\circledast}$ vending machines' (in Australia), 'electronic dispenser', 'distribox ${ }^{\otimes 1}$ or sometimes simply 'slot machines'. New Zealand introduced a mobile dispensing machine which is wheeled to a front doorway and locked there. This design enables exchange services to continue after hours in a safer way [10].

The NSP-mobile van was first introduced one year earlier, in 1986, in Amsterdam, the Netherlands. It was, in fact, a methadone dispensing bus that also offered syringe and needle exchange [11]. In the same year health workers in London and Liverpool started to exchange needles and syringes using mobile vans [12]. In some settings this form of NSP is known as a 'roving van' or 'mobile bus' or simply 'mobile outlet'. Mobile vans have received much more acceptance than dispensing machines and have been introduced more widely.

\section{The rationale for dispensing machines and mobile vans in NSPs}

Each of these approaches offers the potential to provide injecting equipment to hard-to-reach and high-risk groups of IDUs. For example, some IDUs are concerned to remain anonymous and fear that they may be identified if they try to access sterile injecting equipment from pharmacies or conventional NSPs [13-15]. Many IDUs need access to services in the evening, at night or in weekends. These users strongly feel the need for a non-contact and out of business hours service and consequently dispensing machines were introduced to supply sterile needles and syringes together with condoms, health information pamphlets and other minor health supplies [16]. Dodding \& Gaughwin [17] reported that one of the main reasons identified by Australian IDUs for sharing injecting equipment was the relative unavailability of sterile injecting equipment, particularly outside the operating times of pharmacies and conventional NSPs. If attempts are made to continue conventional NSPs at nights and weekends, 
staffing may be difficult or expensive and also staff may see the work as risky. Dispensing machines overcome these staffing problems. The possibility that judgmental attitudes of some pharmacy staff and NSP staff might discourage some IDUs from obtaining sterile injecting equipment $[18,19]$ was another consideration.

Unlike dispensing machines, mobile vans do not provide completely anonymous access to sterile injecting equipment, but peer staffed mobile vans can render a congenial environment that provides near anonymous access. Mobile vans can cover a greater geographic area and can more readily accommodate changes in local conditions. A van of this sort generally follows a relatively consistent route, and parks at a predictable location at a predictable time, although it can change in response to immediate neighbourhoods' conditions (e.g., increased police presence) or to incorporate additional populations of injecting drug users. One van may visit multiple sites in a single outing. It can provide the benefits of both a fixed and a mobile site. In addition, it can also provide shelter and some security for staff, some privacy for clients, and a consistent service while covering a large geographic area. A roving site also keeps staff members and clients relatively inconspicuous to neighbours, local business people, and police officers.

\section{Reaching hidden and hard-to-reach IDUs}

A subgroup of IDUs are largely marginalised, isolated and socially excluded and highly mobile[54]. They are often not in contact with any services, as they are either unaware of them or do not wish to access them. Corr [54] characterised these groups as drug users who are mostly homeless, female, younger, chaotic and from an ethnic minority. Prisoner IDUs form another important highrisk group. Beginner-IDUs are also hard-to-reach and usually do not define themselves as drug addicts and do not approach NSPs or drug treatment units. None of these groups are mutually exclusive and when these characteristics are multiplied in the same individual, the person is likely to suffer increasing marginalisation [55]. They are highly susceptible to potential adverse health outcomes, particularly blood-borne virus infections as their risky behaviours often go unrecognized. Of the studies/reports reviewed, 37 presented data/results on the ability of dispensing machines and/or mobile vans to reach hidden and hard-to-reach IDUs (Table 1).

\section{Dispensing machines}

Few studies have attempted to evaluate whether dispensing machines attract hidden, hard-to-reach or high-risk IDUs. Perhaps the most comprehensive studies were performed in Marseille, France where it was found that primary users of vending machines were significantly younger and less likely to live in a house they personally owned or rented; they were also less likely to have been in opioid maintenance treatment [39]. The researchers concluded that the machine outlet seemed to effectively attract a relatively hidden [7] and high-risk segment of IDUs who are less likely to be reached by other programs [39]. In the same city Moatti et al. [45] reported that users of vending machines were younger than those who

Table I: Ability of NSP-mobile vans and dispensing machines to reach high-risk and/or hidden IDUs.

\begin{tabular}{|c|c|c|c|c|c|}
\hline \multicolumn{3}{|c|}{ Syringe dispensing machines } & \multicolumn{3}{|c|}{ Mobile vans } \\
\hline Ref. & Location & $\begin{array}{l}\text { Reached high-risk } \\
\text { and/or hidden IDUs }\end{array}$ & Ref. & Location & $\begin{array}{l}\text { Reached high-risk } \\
\text { and/or hidden IDUs }\end{array}$ \\
\hline$[20]$ & Vestfold, Norway & Yes & {$[21]$} & Paris, France & Yes \\
\hline [22] & Rotterdam, the Netherlands & Yes & {$[23]$} & Paris, France & Yes \\
\hline$[24]$ & Milan, Italy & Yes & {$[25]$} & Geneva, Switzerland & NM \\
\hline [26] & Sydney, Australia & Yes & {$[27]$} & Rome, Italy & Yes \\
\hline$[28]$ & Berlin, Germany & Yes & [29] & Spain & Yes \\
\hline [30] & Berlin, Germany & Yes & {$[31]$} & Rockville, USA & Yes \\
\hline [32] & New South Wales, Australia & Yes & [33] & Vancouver, Canada & Yes \\
\hline$[17]$ & Perth and Adelaide, Australia & Yes, it will* & [34] & Wisconsin, USA & Yes \\
\hline [35] & Hindelbank, Switzerland & Yes & {$[36]$} & Baltimore, USA & Yes \\
\hline [37] & Realta, Switzerland & Yes & [38] & Sicily, Italy & Yes \\
\hline [39] & Marseille, France & Yes & [8] & Baltimore, USA & Yes \\
\hline$[40]$ & Vechta, Germany & Yes & {$[4 I]$} & St. Petersburg, Russia & Yes \\
\hline [42] & Kalgoorlie, Australia & Yes & {$[43]$} & Oslo, Norway & Yes \\
\hline [9] & Bremen, Germany & NM & {$[44]$} & Sofia, Bulgaria & Yes \\
\hline$[45]$ & Marseille, France & Yes & {$[46]$} & Vancouver, Canada & Yes \\
\hline$[47]$ & Lichtenberg, Lehrter Strasse, Germany & Yes & {$[48]$} & Madrid, Valencia and some other places of Spain & Yes \\
\hline \multirow[t]{2}{*}[49]{} & Hamburg-Vierlande, Germany & NM & {$[50]$} & Vilnius, Lithuania & Yes \\
\hline & & & {$[5 \mathrm{I}]$} & New Heaven, CT, USA & Yes \\
\hline$[52]$ & Canberra, Australia & Yes & {$[53]$} & Melbourne, Australia & Yes \\
\hline
\end{tabular}

\footnotetext{
* Perception of focus group IDUs and health staff. NM = Not mentioned
} 
accessed pharmacy or NSP for needle-syringe and tended to have a lower socioeconomic status. They were significantly less likely than pharmacy users to have a regular job, and more likely than NSP users to be without any resources. Stark et al. [30], in their vending machine study in Berlin, found that machines users were more likely to report a shorter history of injection. The authors explained that early in their injection career IDUs may prefer to obtain injecting equipment anonymously from vending machines. They may not yet consider themselves drug dependent, and may not be willing to contact staffed agencies. This explanation was supported by their findings that only $33 \%$ of the IDUs reported current contacts with counselling units. This rate was significantly lower in those with a shorter history of injecting. Similarly Leicht [28] reported that novice IDUs are the main users of machines with most having no contact with other helping agencies for IDUs'. Based upon the findings of a study in Italy, Agnoletto et al [24] underscored the need for complementary use of both exchange machines and mobile vans to modify risk behaviours of drug users who are not in contact with health services.

Evaluation of dispensing machines in Norway showed that these were a successful method of providing sterile equipment to a group until then difficult to reach [20]. Comparable results had also been observed from all the studies in Australia. Dodding \& Gaughwin [17] reported that because of the small populations in rural towns, the confidentiality of IDUs in those areas can be particularly important and vending machines may be a valuable form of NSP. Most participants (IDUs and health workers) in this study believed that some IDUs in these areas do not use their local NSPs or pharmacies because of concern for anonymity.

Prisoner-IDUs are at very high risk of blood-borne infections. A range of interlinking factors compound this risk the large number of IDUs, scarcity of sterile injecting equipment and correspondingly higher prevalence of needle-syringe sharing, rapid turnover of prison populations and hence far more changes in injecting partners [56]. Syringe exchange machines were found to be very effective in increasing access to sterile injecting equipment in prisons in Switzerland and Germany. Their easier and roundthe-clock access, high-degree of anonymity; better acceptance by inmates and better control of syringe disposal (one-for-one exchange) made these machines a useful mode of syringe exchange. The availability of injecting equipment through dispensing machines did not lead to an increase in drug use or injection frequency and syringe sharing reduced significantly [47]. Stöver \& Jacob [40] reported that anonymous access through exchange machines in a Women's Prison made it more acceptable to the inmates than manual distribution in a Men's
Prison. The authors concluded that the level of acceptance among prisoners largely depended on whether anonymity is maintained during needle exchange. However, unfortunately with political changes, all but one syringe exchange machine in prisons in Germany have been removed. Only Lichtenberg-Berlin still offers syringes.

\section{Mobile vans}

Overall findings suggest that mobile van outlets of NSPs are effective in reaching hidden and high-risk group of IDUs. A large study $(\mathrm{n}=1020)$ in Vancouver compared risk taking behaviours of IDUs attending conventional, and mobile van needle exchanges [46]. This demonstrated increasing risk profiles from IDUs who attend pharmacy, to those who attend conventional NSPs to mobile exchange van clients. Van users were more likely to be younger, Indigenous and female. These results are consistent with another Vancouver study [33], which compared van to conventional NSP users. Van users were found to inject more frequently, inject more frequently on the street, be younger, more likely to engage in sex work and less likely to be enrolled in a drug treatment program.

Riley et al. [36] studied new clients of both a mobile van and of a pharmacy-based NEP in the same neighbourhood in Baltimore. They found that the van attracted twice as many high-frequency injectors. Similarly, "Blue Bus" exchange in Lithuania reports successfully reaching a particular local community, identified as one of the most at risk groups, where injecting drug use is common. A survey conducted to evaluate the impact of the Blue Bus service on injecting practices of its clients revealed that within the previous 30 days $96 \%$ of IDUs reported they did not utilize used syringes, $88 \%$ did not share used syringes and needles with others, and $92 \%$ said they did not buy syringes already filled with a narcotic [50].

According to official data from the Ministry of Health, less than half the IDUs in Rome were in touch with drug dependence treatment units during 1992. However, with the aid of an outreach mobile van, 1023 (52.5\%) new IDUs (who were not attending other services) were provided with services from the van in a one year period during 1992-93 [27]. Similarly, a mobile van outreach program in Spain encountered 1,745 new clients in only a 9 month period [29]. Comparable results have been reported on an evaluation of a pilot program using a camper van in Catania, Sicily. Although the camper van suffered a lack of active support from other drug treatment agencies and organisations, it slowly was able to establish contacts with an increasing number of hidden IDUs [38]. Lhomme et al. [21] reported findings of an evaluation of a NEP in Paris, which introduced mobile vans in its second phase. Of those accessing the program, $60 \%$ were 
homeless and $46 \%$ HIV positive of whom 59\% were without medical follow-up.

\section{Complementary or duplication of services?}

As evidence for the ability of these two types of NSP outlets to reach the hidden, hard-to-rich and high-risk group of IDUs has accumulated, it would be hoped that they complement each other and other modes of NSPs. Only two studies are available that have evaluated both dispensing machines and mobile vans. Agnoletto et al. [24] studied IDUs who used exchange machines and/or mobile vans but were not in contact with other health services in Milan, Italy. The authors concluded that the need to provide non-judgemental access to counselling and information justify complementary utilization of both exchange machines and mobile units as strategies for harm reduction. This observation is in keeping with the findings of a Berlin study that found users of vending machines, low-threshold meeting places and needleexchange buses were significantly different in terms of HIV-rate, history of drug use and contact with counselling units [28]. Therefore they are different target groups for HIV-prevention. The most common three recommendations from IDUs $(\mathrm{n}=76)$ interviewed in Scotland to improve access and quality of services were (i) outreach schemes and vending machines (62\%), (ii) extending opening hours (12\%) and (iii) more privacy in NEP (9\%) [57]. These findings support the relevance of these two outlets in the context of other modes of NSP.

The most important advantage of dispensing machines is their anonymous and off-peak services when other outlets are closed. The findings of French trials consistently found that these machines are a useful adjunct to other modes of NSPs by reaching a different segment of IDUs [39,45]. All four evaluations $[26,32,42,52]$ and a focus group discussion with IDUs [17] in Australia also supported the complementary role of dispensing machines.

Mobile vans mostly provide a flexible outreach service and act as a bridge to fixed-site outlets. For example, in Volgograd (Russian Federation) a fixed-site is augmented by a bus which serves three networks of drug users who live far apart in the city that stretches $40 \mathrm{~km}$ along the Volga river [58]. Similarly, Somlai et al. [34] described a mobile service, Lifepoint, which visits a number of high traffic areas on a rotating basis. These areas include drug houses, taverns, parks, and commercial sex areas. The duration of each visit to each site varies according to drug house locations, seasonal migrations of clients during cold weather, and in response to advice from key informants.

In some countries, amidst strong injecting paraphernalia law and few or no dispensing machine outlets on the grounds of importance of health staff contact, the mobile van can reduce the distance for users to travel to get needles and syringes. Carrying used syringes for a long periods in order to exchange presents problems for IDUs in the presence of police pressure and can dissuade them from bringing used syringes back [38]. The van reduces the risk of being caught by a law enforcing agency. Burrows [58] reminds us that forced closure is the most common reason for NSPs terminating services, and mobile services are often easier for local residents to cope with and can prevent or overcome the opposition that is focused on a fixed-site NSP. On the other hand, some IDUs in Vancouver mentioned the difficulty in meeting the mobile van as one of the major challenges [59], an issue vending machines may address effectively.

Importantly, while dispensing machines ensure great anonymity, they take away the important contact of IDUs with heath staff. In contrast, mobile vans ensure the contact but reduce anonymity.

\section{Discussion}

This review offers evidence to support the notion that dispensing machines and mobile vans can accommodate different patterns of user, diversifying services to meet various needs. Drug use is not confined to a nine-to-five schedule. Practitioner-feedback from the only NSP outlet in Australia that is staffed 24 hours a day and 365 days a year indicates that close to half of the services are provided between $6 \mathrm{pm}$ and 6 am [60]. Nevertheless in many parts of the world, even where NSPs are on a strong platform, there are few if any access points to sterile injecting equipment during these hours. In such a context, the need for a 24-hour service is gravely felt and syringe dispensing machines have emerged as a simple and very effective tool.

It is known that bringing users into contact with people who can support and promote appropriate behaviour change is an important aspect of contemporary NSPs [61]. This aspect has been valued so strongly in the NSPs of USA that it has probably worked against the introduction of dispensing machines [62]. However, it has also been recognised that because of the illicit nature of drug use, some users are reluctant to use services which bring them into contact with anyone, and even the relatively anonymous services provided by local pharmacies [63]. For those people a non-contact service was needed and dispensing machines to supply sterile equipment have emerged as an aid to them.

Syringe dispensing machines are likely to be highly cost effective, and the main saving is in staff costs. Clearly the staff costs would be substantial if a 24 hours staffed service is provided. Berg [26] found that machines could be 
highly self-supporting at lower prices for equipment, and be highly cost-effective even if the equipment was dispensed free-of-cost. However, this cost saving is based only on the cost of provision of sterile equipment and does not take into account the potentially greater health promotion impact via staff-user contact at staffed NSP outlets [64]. On the other hand, a mobile van service can be relatively expensive as, in addition to personnel cost, it involves the purchase and maintenance of a vehicle and fuel costs [58].

However, services through mobile vans can be provided at both locations and times that are compatible with the IDUs' lives. Mobile vans increase accessibility for clients who do not have a vehicle or money for transportation, and/or may be too drug-impaired to drive to the fixed-site. The importance of having a service close to IDUs was observed in a study in New York [65]. The authors found that $81 \%$ of IDUs who lived nearby typically used a NEP compared to $59 \%$ of those who lived further away. In multiple logistic regression analysis, those who lived nearby remained 3 times more likely (adjusted OR $=2.89$; 95\% CI 2.06-4.06) to use NEP, and were less likely to have engaged in receptive syringe sharing at their last injection (adjusted OR $=0.45,95 \%$ CI 0.24-0.86). Therefore, locating NSP services in areas convenient to large numbers of IDUs may be critical for prevention of bloodborne virus infection. It might not always be possible to set up fixed-site NSP in all strategically important points because a range of variables needs to be addressed before attempting to set-up and then make it responsive to the need of IDUs. The mobile van can come to aid in resolving this problem.

Despite having conventional NSPs and pharmacies available, IDUs might experience several barriers in accessing sterile equipment. It was found that those who reported difficulty with accessing sterile needles were 3.5 times more likely to report needle sharing than were people without difficulty [66]. Table 2, we developed, describes some common barriers to NSP access, the majority of which were reported in a study in Sydney [67]. It also helps us understand the likely ability of dispensing machines and mobile vans to improve the accessibility and acceptability of NSPs to IDUs by addressing several barriers that IDUs encounter with the conventional NSPs and pharmacy outlets.

The results of this review do not support one type of NSP outlet over another, rather they suggest that coexistence of different modes and tailoring of services offered at different venues might be an important consideration. There is a convincing body of international experience on the effectiveness of conventional NSPs in providing access to sterile injecting equipment to IDUs, which in many settings cannot be replaced by other modes [68]. Nor on the other hand is it feasible to replace the advantages of a mobile van or dispensing machine by a conventional outlet. Cox et al. [69] recommends comprehensive NSPs including pharmacy involvement in distribution, strategically-placed dispensing machines and mobile exchanges.

Table 2: Standard of good practice of dispensing machine and mobile van to address some common barriers experienced by IDUs in accessing sterile injecting equipment from conventional NSPs and pharmacy outlets.

\begin{tabular}{lll}
\hline Some common barriers to access & Vending Machines' ability to address & Mobile Vans' ability to address \\
\hline Worried about being seen as an IDU & Very good & Moderate \\
Do not feel comfortable to visit NSPs & Very good & Moderate \\
Worried about being seen by parents/relatives & Moderate & Moderate \\
Hours not open when needed & Very good & Moderate \\
Pharmacies do not want to sell & Very good & Very good \\
Did not like attitudes of pharmacy-staff & Very good & Very good \\
Did not know about NSPs & Very good $\alpha$ & Very good $\alpha$ \\
Too far to travel NSPs or Pharmacies & Very good $\alpha$ & Very good $\alpha$ \\
Did not like location of NSPs or Pharmacies & Very good $\alpha$ & Very good $\alpha$ \\
Too many police around NSPs & Very good & Very good \\
Not easy to travel to NSP and pharmacy & Very good $\alpha$ & Very good $\alpha$ \\
NSPs are too busy & Very good & Very good \\
NSP too close to a methadone clinic & Very good $\alpha$ & Very good $\alpha$ \\
Limited equipment available at once & Very good $\beta$ & Very good $\delta$ \\
Did not like NSP staff & Very good & Very good $\gamma$ \\
Did not understand the language & Very good & Moderate \\
NSPs are male dominated & Very good & Moderate $\Omega$
\end{tabular}

$\alpha$ : If strategically important places are covered by dispensing machines and (or) vans; $\beta$ : If needle-syringes are offered for coin or free of cost; $\delta$ : If not strict to one-to-one exchange; $\gamma$ : If peer staff are employed; $\Omega$ : It may be very good if services are gender responsive. 
This review should be considered in the light of several limitations. Firstly, only literature published in the English language was reviewed. Subsequent reviews should consider translating publications in other languages to capture a greater range of evidence. Secondly, most of the literature originated from developed countries and may not be generalizable to the conditions of developing countries where the vast majority of the world's IDUs now live. Thirdly, there is a paucity of data even in the grey literature. In addition, the articles reviewed may be subject to various biases.

\section{Conclusion}

There is persuasive evidence that different venues of NSP attract different clients. In particular, dispensing machines and mobile vans are preferred modalities for hidden and high-risk IDUs. These two modalities can successfully address concerns about temporal and spatial accessibility and overall acceptability of NSP. Intrinsic advantages of each can offset the shortcomings of the other. Despite the relatively small volume of publications a clear and consistent finding is that these two outlets, if set up properly in a well chosen location with the local community well prepared, can generally increase the availability of sterile injecting equipment at times and places where coverage is poor. They also may enhance NSP provision through providing anonymous and confidential access to sterile injecting equipment for hidden and high-risk groups of IDUs.

\section{Statement of competing interests}

The author(s) declare that they have no competing interests.

\section{Authors' contributions}

MMI conceived of the review, collected the available background articles/reports on this topic and wrote the first draft of the manuscript. KMC critically analysed the manuscripts, corrected and revised all the versions. Both the authors read and approved the final manuscript.

\section{Acknowledgements}

The first author gratefully acknowledges the relevant authority of AusAID for awarding him ADS scholarship for Masters Programme. He also acknowledges the Government of Bangladesh for giving him deputation for higher study. He is delighted to acknowledge Dr Richard Hillman of STIRC for his all out assistance in Masters Programme.

The authors gratefully recognise the assistance of Libraries of the University of Sydney.

\section{References}

I. WHO: Harm Reduction Approaches to Injecting Drug Use. 2005 [http://www.who.int/hiv/topics/harm/reduction/en/]. Retrieved September 2005

2. WHO-Regional Office for Southeast Asia: HIVIAIDS Prevention and Control. 2005 [http://w3.whosea.org/EN/Section I0/Section /8/ Section2009 9939.htm]. Retrieved October 2005
3. UNAIDS/WHO: Epidemiological Fact Sheet - Ukraine 2004 Update. [http://www.unaidsorg/en/media/factsheetsasp]. accessed IOth November 2004

4. Wodak A: Hepatitis C: Waiting for the grim reaper. Medical Journal of Australia 1997, 166:284-285.

5. Crofts N Aitken CK, Kaldor JM: The force of numbers: Why hepatitis $C$ is spreading among Australian injecting drug users while HIV is not. Medical Journal of Australia 1999, 170:220-221.

6. Strike CJ Challacombe L, Myers T, Millson M: Needle Exchange Programs: Delivery and Access Issues. Canadian Journal of Public Health 2002, 93(5):339-343.

7. Berger A: Vending machine enlisted in AIDS fight. In New York Times Volume December 28, F7 (col. I). New York; 1999.

8. Riley ED Vlahov D, Safaeian M, Marx MA, Beilenson P, Strathdee S: Drug users participating in mobile needle exchange report higher HIV risk behaviors than those participating in pharmacy-based needle exchange: San Francisco. ; 2000.

9. Anonymous: German towns fund syringe automat for injectors. Druglink 1989, 4(5):6.

10. Aitken C: New Zealand needle and syringe exchange programme review final report. Wellington, The Center for Harm Reduction; 2002.

II. Moore G McCarthy P, MacNeela P, MacGabhann L, Philbin M, Proudfoot D: A Review of Harm Reduction Approaches in Ireland and Evidence from the International Literature. Dublin , National Advisory Committee on Drugs; 2004.

12. Buning E: Outreach work with drug users: an overview. International Journal of Drug Policy 1993, 4(2):78-82.

13. Sharp R Davis M, Dowsett GW, Kippax S, Hewitt K, Morgan S, Robertson W: Ways of using: functional injecting drug users' project. Sydney, NSW Health Department; 1991.

14. Stöver $\mathrm{H}$ : Evaluation of needle exchange pilot projects shows positive results. Canadian HIVIAIDS Policy \& Law Newsletter 2000, 5(2/3):60-64.

15. Strathdee SA Vlahov D: The effectiveness of needle exchange programs: A review of the science and policy. AIDScience 200I, I(16): I-3I.

16. Loxley W Watt P, Kosky M, Westlund B, Watson C, Marsh A: Western Australian initiatives to prevent the spread of HIVIAIDS amongst injecting drug users. International Journal on Drug Policy 1991, 2(4): 13-16.

17. Dodding J Gaughwin M: The Syringe in the machine. Australian Journal of Public Health 1995, 19:406-409.

18. Gleghorn AA Gee G, Vlahov D: Pharmacists' attitudes about pharmacy sale of needles/syringes and needle exchange programs in a city without needle/syringe prescription laws. Journal of Acquired Immune Deficiency Syndromes and Human Retrovirology 1998, I 8((SuppI I)):S89-S93 .

19. Wright-De Agüero L Weinstein B, Jones TS, Miles J: Impact of the change in Connecticut syringe prescription laws on pharmacy sales and pharmacy managers' practices . Journal of Acquired Immune Deficiency Syndromes and Human Retrovirology 1998, 18((Suppl I)):SI02-SIIO.

20. Corr C: Reaching the 'Hard to Reach': Dublin Castle, Ireland. ; 2002.

21. Starmans R: 'Marginalised Groups'. In Management of Drug Users in the Community: A Practical Handbook Edited by: Robertson R. London: Arnold ; 1998.

22. Obadia Y Feroni I, Perrin V, Vlahov D, Moatti JP: Syringe vending machines for injecting drug users: an experiment in Marseille, France. American Journal of Public Health 1999, 89(12): I582-1584.

23. Moatti JP Vlahov D, Feroni I, Perrin V, Obadia Y: Multiple access to sterile syringes for injection drug users: vending machines, needle exchange programs and legal pharmacy sales in Marseille, France. Eur Addict Res 2001, 7:40-45.

24. Stark K Leicht $A$, Müller R: Characteristics of users of syringe vending machines in Berlin. Sozial und Praventivmedizin 1994, 39(4):209-216.

25. Leicht A: Characteristics and HIV-infection of users of syringe vending-machines and exchanging programs in Berlin/Germany: Berlin, Germany. ; 1993.

26. Agnoletto V Tradati C, Ceserani N, Capra E, Andolina P, Lesomo C: Street work and needle exchange machines as complementary strategies of HIV harm reduction among active drug 
users: an Italian model (Abstract no. WS-D09-4): Berlin,

Germany.

1993.

27. Diseth TH: The syringe dispenser project in Larvik: Experience after one year. (Abstract, PMID: 2595707). Tidsskr Nor Laegeforen 1989, 109(32):3345-3348

28. Dolan K Rutter S, Wodak A: Prison-based syringe exchange programmes: a review on international research and development. Addiction 2003, 98: I53-158.

29. Stöver $\mathrm{H}$ Nelles J: Ten years of experience with needle and syringe exchange programmes in European prisons. International Journal of Drug Policy 2003, 14:437-444.

30. Stöver $\mathrm{H}$ Jacob J: The transfer of harm-reduction strategies into prisons: needle exchange programmes in two German prisons. International Journal of Drug Policy 2000, I I:325-335.

31. Miller CL Tyndall M, Spittal P, Li K, Palepu A, Schechter MT: Risktaking behaviors among injecting drug users who obtain syringes from pharmacies, fixed sites and mobile van needle exchanges. Journal of Urban Health 2002, 79(2):257-265.

32. Schechter M Currie S, Strathdee SA, O'Shaughnessy MV, Patrick DM, Rekart ML, Turvey J, Schechver MT: Maximizing needle exchange coverage among injection drug users (IDUs): do mobile programs attract those at highest risk?: Geneva, Switzerland. ; 1998.

33. Riley ED Safaeian M, Strathdee S, Marx MA, Huettner S, Beilenson P, Vlahov D: Comparing new participants of a mobile versus a pharmacy-based needle exchange program. JAIDS Journal of Acquired Immune Deficiency Syndromes 2000, 24(I):57-6I.

34. Subata E Kriksciukaityte R: Harm reduction programs in Vilnius, the capital of Lithuania. In HIVIAIDS prevention amongst injecting drug users in Lithuania:Best practices Edited by: LITINTERP . Vilnius, Lithuania , Central and Eastern European Harm Reduction Network; 2003.

35. De Rugeriis E Patruno F, Arcari P, Zaccarelli M, Paciello T, Barra M: The outreach program for injecting drug users in Rome: Berlin, Germany. ; 1993.

36. Colomo C Estebanez P, Merodio C, Fitch K, Munoz M, Garcia Lalinde $G$ : Mobile unit for syringe exchange and condom distribution in a health education program: Berlin, Germany. ; 1993.

37. Nigro L Casciaro A, Matalone M, Aloisio P, Bruno S, The Unit Operators Group: Feasibility in needle exchange programme: an evaluation of a pilot programme in Catania, Sicily. International Journal of Drug Policy 2000, I I :299-303.

38. Lhomme JP Edwige A, llie C, Regnier AF, Gehant A: Evaluating the first syringe exchange program in Paris: Amsterdam, Netherlands. ; 1992

39. Glasgow Involvement Group \& April Shaw (SDF Research Officer) Glasgow , Scottish Drugs Forum: Views from the street: Needle exchange Users in Glasgow. 2005 [http://www.sdf.org.uk/sdf/ files/Glasgow\%20needleexchangestudy.pdf]. Retrieved May 2006

40. Berg R: Needle and syringe vending machine trial evaluation report I. Sydney, NSW Department of Health; 1993.

4l. Berg R: Needle and syringe vending machine trial evaluation report 2. Albury, Sydney, NSW Department of Health; 1995.

42. Moloney A: Evaluation of the fitpacks vending machine trial at Kalgoorlie regional hospital, Australia. Kalgoorlie, Northern Goldfields Health Services Public \& Community Health; 200I.

43. McDonald D: ACT Syringe vending machines trial 2004-2006. Canberra, Australia ; 2005.

44. Burrows D: Starting and managing needle and syringe programs: a guide for central and eastern Europe and the newly independent states of the former soviet union. Edited by: Derricott APJ. New York , International Harm Reduction Development; 2000.

45. Somlai AM Kelly JA, Otto-Salaj L, Nelson D: "Lifepoint": A case study in using social science community identification data to guide the implementation of a needle exchange program. AIDS Education and Prevention 1999, I I (3): 187-202.

46. Wood E Tyndall MW, Spittal PM, Li K, Hogg RS, O'Shaughnessy MV, Schechter MT: Needle exchange and difficulty with needle access during an ongoing HIV epidemic. International Journal of Drug Policy 2002, I 3:95-102.

47. Govt. of Bangladesh: HIV in Bangladesh: The Present Scenario. In A summary of key findings from the fifth round of serological and behaviour surveillance for HIV in Bangladesh (2003-2004) National AIDS/STD Programme, Directorate General of Health Services, Ministry of Health \& Family Welfare; 2004.
48. Stimson GV Donoghoe M, Alidritt L, Dolan K: HIV transmission risk behaviour of clients attending syringe-exchange schemes in England and Scotland. British Journal of Addiction 1988, 83: |449-| 455 .

49. Fuller J: Needle Exchange: Saving Lives. America 1998, I 79:8-I I.

50. Islam MM, Conigrave KM: Syringe vending machines as a form of needle syringe program: Advantages and Disadvantages. Journal of Substance Use 2007, I 2(3):203 -22I2.

5I. Islam MM, Wodak A, Conigrave CM: The effectiveness and safety of syringe vending machines as a component of needle syringe programmes in community settings. International Journal of Drug Policy (in press) 2007.

52. Burrows D: Starting and managing needle and syringe programs: a guide for central and eastern Europe and the newly independent states of the former Soviet Union. Edited by: Derricott APJ. New York, International Harm Reduction Development; 2000.

53. Rockwell R Des Jarlais DC, Friedman SR, Perlis TE, Paone D: Geographic proximity, policy and utilization of syringe exchange programmes. Aids Care 1999, I I (4):437-442.

54. Wood E Tyndall MW, Spittal P, Li K, Hogg RS, O'Shaughnessy M, Schechter MT: Predictors of Persistent High-Risk Syringe Sharing During an Ongoing HIV Epidemic. Canadian Journal of Infectious Diseases 200I, I2 (Suppl. B).(Suppl. B):.

55. Treloar $C$ Cao $W$ : Barriers to use of needle and syringe programmes in a high drug use area of Sydney, New South Wales. International Journal of Drug Policy 2005, I 6:308-3 I 5.

56. Southgate E Blair D, Hopwood M: Social and health impact study: The closure and relocation of the St Marys needle \& syringe program. Sydney, National Center in HIV Social Research; 2000.

57. Cox G Lawless M, Cassin SP, Geoghegan TW: Syringe exchanges: A public health response to problem drug use. Irish Medical Journal 2000, 93(5): | $43-146$

58. Klaassen R: Syringe exchange by automat. The International Journal of Drug Policy 1989, I (3):6-7.

59. Edwige A Aeberhard F, Benarosch J, Gehant A, Lhomme JP: IVDU population of Medecins du Monde's mobile unit. "Syringe exchange": Amsterdam, Netherlands. ; 1992

60. Hausser D Mani C, Malatesta D, Joye D: BIPS bus itinerant prevention SIDA (mobile AIDS prevention unit) in Geneva (Switzerland) for drug injectors: Amsterdam, Netherlands. ; 1992.

61. McConnell W Rael M, Hewitt W, Mata A, Austin B: The efficacy of using mobile vans while providing outreach services to high risk substance abusers: Yokohama, Japan. ; 1994.

62. Nelles J Dobler-Mikola A, Kaufmann B: Provision of syringes and prescription of heroin in prison: The Swiss experience in the prisons of Hindelbank and Oberschöngrün. In Harm reduction in prison (pp 239-262) Edited by: J Nelles \& A Fuhrer. Berne, Peter Lang ; 1997.

63. Nelles J Fuhrer A, Vincenz I: Drug, HIV and hepatitis prevention in the Realta Contonal men's prison: Summary of the evaluation. Bern , Swiss Federal office of Public Health; 1999.

64. Tsekhanovich A: Reaching drug users through mobile services for HIV prevention. In Drug Abuse and HIVIAIDS: Lessons Learned Edited by: Hedrich D. Vienna and Geneva , UNDCP/UNAIDS; 2001:35-38.

65. Miller M Eskild A, Mella I, Moi H, Magnus P: Gender differences in syringe exchange program use in Oslo, Norway. Addiction 2001, 96:1639-1651.

66. Nikolov Z: Outreach work on HIVIAIDS prevention among out-of-treatment injecting drug users. In Drug Abuse and HIVI AIDS: Lessons Learned Edited by: Hedrich D. Vienna and Geneva , UNDCP/UNAIDS; 200I:I6-2I.

67. Estebanez P Arenas MAR, Manez AS, Alvaro JR, Garcia AB: Main tendencies of injecting drug users feature in the mobile units of the programs of outreach syringes exchange programs of Medicos del Mundo: Barcelona, Spain. ; 2002.

68. Heinemann A Gross U: Prevention of blood borne virus infections among drug users in an open prison by syringe vending machines. Sucht 200I, 47(I):57-65.

69. Khoshnood K Kaplan EH, Heimer R: 'Dropouts' or drop-ins'? Client retention and participation in New Haven's Needle Exchange Program. Public Health Reports 1995, I I 0(4):462-466. 
70. Fitzgerald J McDonald K, Klugman M: Unspoken but ever present: Hepatitis C in a regional setting. Melbourne, Centre for the Study of Health \& Society and The Sociology Program, University of Melbourne; 2004.

Publish with Bio Med Central and every scientist can read your work free of charge

"BioMed Central will be the most significant development for disseminating the results of biomedical research in our lifetime. " Sir Paul Nurse, Cancer Research UK

Your research papers will be:

- available free of charge to the entire biomedical community

- peer reviewed and published immediately upon acceptance

- cited in PubMed and archived on PubMed Central

- yours - you keep the copyright

Submit your manuscript here:

http://www.biomedcentral.com/info/publishing_adv.asp 